\title{
Activation of STAT3 is a marker of poor prognosis in human colorectal cancer
}

\author{
TAKAFUMI KUSABA ${ }^{1,2}$, TOSHIYUKI NAKAYAMA ${ }^{1}$, KAZUYUKI YAMAZUMI $^{1,2}$, YUICHI YAKATA ${ }^{1}$, \\ AYUMI YOSHIZAKI ${ }^{1}$, KENICHIRO INOUE $^{3}$, TAKESHI NAGAYASU ${ }^{2}$ and ICHIRO SEKINE $^{1}$ \\ Departments of ${ }^{1}$ Molecular Pathology, ${ }^{2}$ Translational Medical Sciences, Nagasaki University \\ Graduate School of Biomedical Sciences, ${ }^{3}$ Shunkaikai Inoue Hospital, Nagasaki, Japan
}

Received December 22, 2005; Accepted February 20, 2006

\begin{abstract}
It is known that the signal transducer and activator of transcription 3 (STAT3) is a key signaling molecule implicated in the regulation of growth and malignant transformation. Constitutive activation of STAT3 has been observed in a number of tumour-derived cell lines, as well as in a wide variety of human malignancies. The present study was conducted to examine p-STAT3 (activated form of STAT3) expression and its association with clinicopathological factors and prognosis in human colorectal adenocarcinomas. Expression of p-STAT3 was immunohistochemically examined in 108 cases of colorectal adenocarcinoma tissue obtained at surgery. and was found in $57.4 \%$ of tumours (62 of 108). p-STAT3 immunoreactivity significantly correlated with the depth grading of tumour invasion $(\mathrm{p}<0.001)$, lymphatic invasion $(\mathrm{p}<0.05)$, Dukes' classification $(\mathrm{p}<0.05)$, stage $(\mathrm{p}<0.001)$ and prognosis after operation $(\mathrm{p}<0.001)$. Expression of $\mathrm{p}-\mathrm{STAT} 3$ was a marker of poor prognosis in overall survival $(\mathrm{p}<0.01)$. Expression of p-STAT3 was detected by Western blot analysis in three colon carcinoma tissue samples obtained at surgery.To our knowledge, this is the first study on the poor prognosis of p-STAT3 in human colorectal adenocarcinomas. These findings suggest that expression of p-STAT3 is an important factor related to tumour invasion and poor prognosis of human colorectal adenocarcinoma.
\end{abstract}

\section{Introduction}

Colorectal cancer is one of the most common malignancies in developed countries $(1,2)$. The incidence of colorectal cancer

Correspondence to: Dr Toshiyuki Nakayama, Department of Molecular Pathology, Nagasaki University Graduate School of Biomedical Sciences, 1-12-4 Sakamoto, Nagasaki, 852-8523, Japan E-mail: toshi-n@net.nagasaki-u.ac.jp

Abbreviations: STAT, signal transducer and activator of transcription

Key words: colorectal cancer, invasion, overall survival, prognosis, p-STAT3 has been increasing dramatically in Japan (3) and has attracted worldwide attention. The prognosis of colo-rectal cancer patients is based on the depth of tumour cell invasion and the presence of lymph node metastasis (4). Usually, these parameters can be determined by microscopic examination of tissue sections from the primary neoplasm and lymph nodes (5). However, it is not always possible to establish a prognosis based only on the histopathological examination of primary colorectal carcinoma specimens (5). Recently, the suggestion was made that the occurrence and progression of cancer is related to the activation of an intra-cellular signaling pathway (6). However, the mechanism of the invasion of colorectal carcinomas has not been fully determined.

Signal transducers and activators of transcription (STATs) are cytoplasmic transcription factors, and are also key mediators of cytokine and growth factor signaling pathways (7). At present, seven mammalian STAT genes have been identified (8-10). The proteins corresponding to these genes have a conserved structural organization consisting of $750-850$ amino acids. The binding of a cytokine to its cognate receptor rapidly induces the tyrosine phosphorylation of the receptor by Jak kinases. Such phosphorylated tyrosines provide docking sites for STATs. The STATs themselves are phosphorylated. The phosphorylated STATs (p-STATs) are released from the receptor, and can then dimerize. The dimeric form can then translocate into the nucleus, where it modulates expression of target genes (11).

A growing number of tumour-derived cell lines, as well as tumour specimens from human cancers, have been reported to express constitutively activated STAT proteins, which are very frequently STAT3 (6). Constitutive activation of STAT3 has been detected in cancers of the pancreas, the prostate, the ovaries, the head and neck, as well as in other cancers (12-15). Our previous study was conducted to explore the relationship between p-STAT3 expression and clinicopathological features in human colorectal adenocarcinoma and adenoma (16). This was the first study to report a significant correlation of p-STAT3 expression with the depth grading of tumour invasion. However, no study had reported a significant association between p-STAT3 expression and prognosis in human colorectal cancer. The present study, therefore, was conducted to explore the relationship between p-STAT3 expression and prognosis in human colorectal cancer. 


\section{Materials and methods}

Cases and tissues. One hundred and eight primary human colorectal adeno-carcinomas were studied by immunohistochemistry. Of the 108 patients with colorectal carcinoma, there were 66 males and 42 females. The median age was 65.6 years (range, 44 to 86 years). Forty-four tumours were located in the rectum, 38 in the sigmoid colon, 4 in the descending colon, 10 in the transverse colon, 10 in the ascending colon and 2 in the caecum. All tumours were obtained from patients who had undergone surgery at Inoue hospital in Nagasaki between 1994 and 1998.

Each tumour was assigned a histological type according to the World Health Organization classification: well differentiated adenocarcinoma, moderately differentiated adenocarcinoma, poorly differentiated adenocarcinoma, and mucinous adenocarcinoma (17).

According to the TNM staging system of the American Joint Committee on Cancer, the depth grading of tumour invasion in each of the carcinomas was classified into 4 groups: $\mathrm{T} 1$, invading submucosa; $\mathrm{T} 2$, invading muscularis propria; T3, invading either subserosa or pericolic tissue; and T4, invading through serosa or invading contiguous organs (18). Staging of the tumours was also conducted according to the American Joint Committee on Cancer, after histological studies.

Based on Dukes' classification, the pathological stages of colorectal carcinoma were classified into 4 groups: A, tumour invading submucosa or muscularis propria; B, tumour extending beyond muscularis propria; $\mathrm{C}$, tumour extending with metastases to regional mesenteric lymph nodes without evidence of distant spread; and D, tumour extending with distant metastasis to other sites, commonly the liver and lungs (19-21).

Lymphatic and venous invasion was studied on routine hematoxylin and eosin-stained slides. In addition, the Elastica van Gieson stain was used in all cases. Each parameter was defined as "present" only when invasion was identified with certainty, but defined as "absent" when not observed at all or not observed with certainty $(22,23)$.

Lymph node metastasis was defined as "present" only when confirmed histologically. The diagnosis was established by two independent pathologists (T. Kusaba and T. Nakayama).

Among the 108 patients, 66 remained disease-free for a median follow-up period of 43.7 months, ranging from 0.71 to 60.0 months. In total, 42 patients suffered from local recurrence and/or distant metastasis after the operation, including 16 patients with local recurrence (two also with distant metastasis), and 26 patients with distant metastasis without local recurrence.

Immunohistochemistry. Formalin-fixed and paraffin-embedded tissues were cut into 4-mm sections, deparaffinized in xylene and rehydrated in phosphate-buffered saline. Deparaffinized sections were preincubated with normal bovine serum to prevent nonspecific binding, and then incubated overnight at $4^{\circ} \mathrm{C}$ with an optimal dilution $(1 \mathrm{ug} / \mathrm{mg})$ of a primary goat polyclonal IgG against human p-STAT3 (Tyr705; Santa Cruz Biotechnology Inc., Santa Cruz, CA, USA). The slides were then incubated with alkaline phosphatase-conjugated

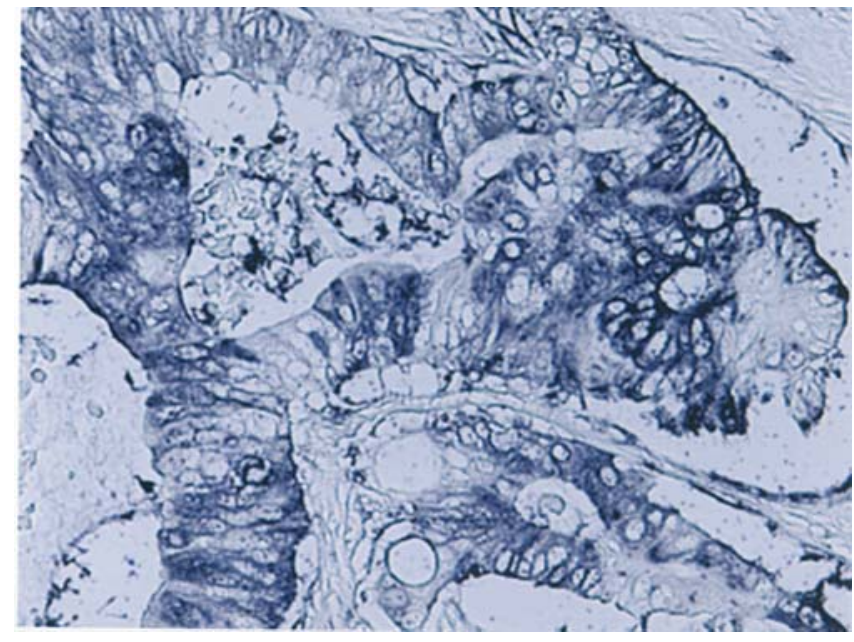

Figure 1. Immunohistochemistry of p-STAT3 in colorectal adenocarcinomas. p-STAT3 shows strong nuclear and cytoplasmic expression. (immunoalkaline phosphatase staining; original magnification, 400X).

donkey anti-goat immunoglobulin antibody (Santa Cruz Biotechnology, Inc.). The reaction products were resolved using a mixture of 5-bromo-4-chloro-3-indolyl phosphate and nitroblue tetrazolium chloride (BCIP/NBT; Dako, Carpinteria, CA, USA). Primary antibody preabsorbed with excess recombinant p-STAT3 peptide (Santa Cruz Biotechnology, Inc.) was used for the negative controls. Prostatic tissue served as the internal positive control for $\mathrm{p}$-STAT3 immunostaining (24).

Analysis of the immunohistochemical staining was performed by two investigators (T. Kusaba and T. Nakayama). p-STAT3 expression was classified into two categories, depending on the percentage of cells stained: negative, 0 to $15 \%$ positive cells; Positive, $>15 \%$ positive tumour cells.

Immunoblotting. Specimens and cells were resuspended in icecold Radioimmunoprecipitation (RIPA) buffer (1X PBS, $1 \%$ Nonidet P-40, $0.5 \%$ sodium deoxycholate, $0.1 \%$ SDS, $1 \mathrm{mM}$ phenylmethylsulfonyl fluoride, $1 \mathrm{mM} \mathrm{Na}_{3} \mathrm{VO}_{4}, 50 \mathrm{mM} \mathrm{NaF}$, and one tablet of complete proteinase inhibitor mixture (Roche Applied Science, Indianapolis, IN) per $50 \mathrm{ml}$ for $10 \mathrm{~min}$, sonicated on ice, and centrifuged $\left(12,000 \mathrm{x} \mathrm{g}, 15 \mathrm{~min}\right.$ at $\left.4^{\circ} \mathrm{C}\right)$. The protein concentration of the supernatant (protein fraction) was determined by Bradford protein assay (Bio$\mathrm{Rad}$, Hercules, CA). An aliquot of $10 \mu \mathrm{g}$ of protein was mixed with an equivalent volume of $2 \mathrm{X}$ protein loading buffer containing 2-ß-mercaptoethanol and boiled for $5 \mathrm{~min}$ before loading onto an SDS-polyacrylamide gel. After electrophoresis, the proteins were transferred onto nitrocellulose membranes using ECL (Amersham Biosciences, Piscataway, $\mathrm{NJ})$ and blocked in TBST (50 mM Tris- $\mathrm{HCl}, \mathrm{pH} 7.5,150$ $\mathrm{mM} \mathrm{NaCl}, 0.05 \%$ Tween-20) containing 5\% non-fat dry milk powder. Protein immunoblots were performed using specific antibodies to B-actin (clone JLA20; Calbiochem San Diego, CA), phosphotyrosine (Tyr ${ }^{705}$ ) STAT3 (Cell Signaling Technology, Beverly, MA), STAT3 (Santa Cruz Biotechnology Inc.). The membranes were further incubated with peroxidase-conjugated secondary antibodies, and protein 
bands were visualized using a commercial chemiluminescence detection kit (ECL Plus; Amersham Biosciences) as described by the manufacturer.

Statistical analysis. The Stat View II program (Abacus Concepts, Inc., Berkeley, CA) was used for statistical analyses. Analyses comparing expression of p-STAT3 were performed with the Chi-square for independence and Mann-Whitney's U test. The Kaplan-Meier method was used in the survival analysis. A log-rank test was used to calculate the significance of differences in the survival analysis. A probability level of less than $0.05(\mathrm{p}<0.05)$ was considered to indicate a significant difference.

\section{Results}

We statistically analyzed the correlation between p-STAT3 immunoreactivity and age, gender and the site of the primary tumour. However, there was no correlation.

Among the 108 adenocarcinomas, histologically, 50 were well differentiated, 50 were moderately differentiated, 4 were poorly differentiated adenocarcinomas and 4 were mucinous carcinomas. There were 30 submucosal infiltrative carcinomas (T1), 14 carcinomas invading proprial muscle layers (T2), 64 carcinomas reaching the subserosa (T3), and none classified as T4. Seventeen cases had lymph node metastasis.

Fig. 1 shows a representative example of strong immunohistochemical p-STAT3 staining in an invasive carcinoma of T3 grade. p-STAT3 protein was detected in both the cytoplasm and the nucleus of almost all carcinomas. The relationships between p-STAT3 immunoreactivity of the tumour cells and pathological features in adenocarcinomas are summarized in Table I. A total of $57.4 \%$ (62/108) of colorectal adenocarcinoma cells showed immunoreactivity for p-STAT3. p-STAT3 expression was found in $56.0 \%$ $(28 / 50)$ of well differentiated adenocarcinomas, $64.0 \%$ (32/50) of moderately differentiated adenocarcinomas, $50.0 \%$ $(2 / 4)$ of poorly differentiated adenocarcinomas, and $0 \%(0 / 4)$ of mucinous carcinoma. There was no significant correlation between p-STAT3 immunoreactivity and the differentiation of colorectal adenocarcinomas.

p-STAT3 immunoreactivity was compared with the depth grading of tumour invasion. p-STAT3 expression was found in $20.0 \%(6 / 30)$ of $\mathrm{T} 1$, in $28.6 \%(4 / 14)$ of $\mathrm{T} 2$, and in $81.3 \%$ (52/64) of T3. A significant correlation was found between p-STAT3 immunoreactivity and the depth grading of tumour invasion $(\mathrm{p}<0.001)$. The incidences of lymphatic invasion and venous invasion were $75.9 \%(82 / 108)$, and $46.3 \%$ (50/108), respectively. p-STAT3 immunoreactivity significantly correlated with the presence of lymphatic invasion $(\mathrm{p}<0.05)$.

The incidence of lymph node metastasis was $31.5 \%$ (34/108), but p-STAT3 immunoreactivity did not significantly correlate with the presence of lymph node metastasis. p-STAT3 immunoreactivity was compared with Dukes' classification. p-STAT3 expression was found in 29.4\% (10/34) of Dukes' A, in $87.5 \%$ (28/32) of Dukes' B, in $68.8 \%$ (22/32) of Dukes' $\mathrm{C}$, and in $25.0 \%(2 / 8)$ of Dukes' D. Immunoreactivity for p-STAT3 significantly correlated with increasing stages of Dukes' classification $(\mathrm{p}<0.001)$.

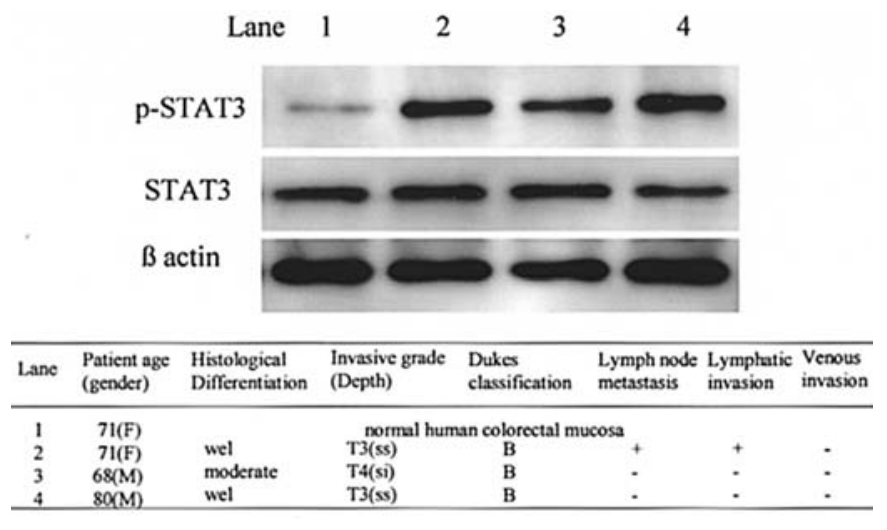

Figure 2. The expression of phosphorylated (activated) signal transducer and activator of transcription (p-STAT3) is lower in normal mucosa (lanes 1) than in adenocarcinoma (lanes 2-4). There is no difference in the expression of STAT3 between the normal mucosa and carcinoma tissues. $\beta$ Actin was used as an internal protein control.

Fig. 2 shows the results of Western blotting for p-STAT3 in surgical specimens of human colorectal cancer. STAT3 expression was detected in all samples. p-STAT3 expression was detected in normal colon mucosa (lane 1), whereas strong expression of p-STAT3 was seen in the colon carcinoma tissues (lanes 2-4).

p-STAT3 immunoreactivity was compared with the stage classification. p-STAT3 expression was found in $20.0 \%$ $(6 / 30)$ of stage I, in $95.0 \%(38 / 40)$ of stage II, in $50.0 \%$ $(16 / 32)$ of stage III, and in $33.3 \%$ (2/6) of stage IV. p-STAT3 immunoreactivity was significantly lower in stage I than stage II-IV $(\mathrm{p}<0.001)$.

p-STAT3 immunoreactivity was compared with prognosis after surgery. p-STAT3 expression was found in $42.4 \%$ $(28 / 66)$ of disease-free and in $81.0 \%$ (34/42) of recurrence and/or metastasis. There was a significant difference in the expression of p-STAT3 with prognosis after surgery $(\mathrm{p}<0.05)$.

Patients with significant constitutively activated STAT3 had worse overall survival than those with negative p-STAT3 (Fig. 3A; log-rank test, $\mathrm{p}<0.001$ ). Moreover, at grade T3 or T4, patients who had p-STAT3 positive staining results had significantly worse overall survival than those who had p-STAT3 negative staining results (Fig. 3B; log-rank test, $\mathrm{p}<0.05$ ). At Dukes' grade A or B, p-STAT3-positive patients had significantly worse overall survival than p-STAT3-negative patients (Fig. 3C; ${ }^{\dagger} \log$-rank test, $\mathrm{p}<0.05$ ). At Dukes' grade $\mathrm{C}$ or D, p-STAT3-positive patients had significantly worse overall survival than p-STAT3 negative patients (Fig. 3C; $\dagger \log$-rank test, $\mathrm{p}<0.01$ ). At stages I or II, p-STAT3-positive patients had significantly worse overall survival than p-STAT3negative patients (Fig. 3D; ${ }^{\dagger} \log$-rank test, $\mathrm{p}<0.01$ ). At Stage III, p-STAT3-positive patients had significantly worse overall survival than p-STAT3-negative patients (Fig. 3D; ${ }^{\dagger \dagger}$ log-rank test, $\mathrm{p}<0.05$ ). At the presence of lymphatic invasion, $\mathrm{p}-\mathrm{STAT} 3-$ positive patients had significantly worse overall survival than p-STAT3-negative patients (Fig. 3E; log-rank test, $\mathrm{p}<0.01)$.

We analyzed disease-free survival as a function of the results of p-STAT3 staining, p-STAT3 staining combined 
Table I. Relationships between p-STAT3 immunoreactivity of tumor and pathological features.

\begin{tabular}{|c|c|c|c|}
\hline & \multirow[b]{2}{*}{$\mathrm{n}$} & \multicolumn{2}{|c|}{ p-STAT3 immunoreactivity, n (\%) } \\
\hline & & + & - \\
\hline Number of patients & 108 & $62(57.4)$ & $46(42.6)$ \\
\hline \multicolumn{4}{|l|}{ Clinical parameters } \\
\hline \multicolumn{4}{|l|}{ Age (years) } \\
\hline Range & $44-86$ & $44-86$ & $45-85$ \\
\hline Mean & 65 & 66 & 65 \\
\hline Median \pm s.d. & $65.6 \pm 10.5$ & $64.9 \pm 12.0$ & $66.1 \pm 8.44$ \\
\hline \multicolumn{4}{|l|}{ Gender } \\
\hline Male & 66 & $38(57.6)$ & $28(42.4)$ \\
\hline Female & 42 & $24(57.1)$ & $18(42.9)$ \\
\hline \multicolumn{4}{|l|}{ Primary site } \\
\hline Caecum/Ascending colon & 12 & $10(83.3)$ & $2(16.7)$ \\
\hline Transverse colon & 10 & $6(60.0)$ & $4(40.0)$ \\
\hline Descending colon & 4 & $4(100)$ & $0(0)$ \\
\hline Sigmoid colon & 38 & $18(47.4)$ & $20(52.6)$ \\
\hline Rectum & 44 & $24(54.5)$ & $20(45.5)$ \\
\hline \multicolumn{4}{|l|}{ Differentiation } \\
\hline Well & 50 & $28(56.0)$ & $22(44.0)$ \\
\hline Moderate & 50 & $32(64.0)$ & $18(36.0)$ \\
\hline Poor & 4 & $2(50.0)$ & $2(50.0)$ \\
\hline Mucinous carcinoma & 4 & $0(0)$ & $4(100)$ \\
\hline \multicolumn{4}{|c|}{ Depth grading of tumour invasion ${ }^{\mathrm{a}}$} \\
\hline $\mathrm{T} 1$ & 30 & $6(20.0)$ & $24(80.0)$ \\
\hline $\mathrm{T} 2$ & 14 & $4(28.6)$ & $10(71.4)$ \\
\hline $\mathrm{T} 3$ & 64 & $52(81.3)$ & $12(18.7)$ \\
\hline $\mathrm{T} 4$ & 0 & $0(0)$ & $0(0)$ \\
\hline \multicolumn{4}{|l|}{ Lymph node metastasis } \\
\hline Absent & 74 & $46(62.2)$ & $28(37.8)$ \\
\hline Present & 34 & $16(47.1)$ & $18(52.9)$ \\
\hline \multicolumn{4}{|l|}{ Lymphatic invasion ${ }^{\mathrm{b}}$} \\
\hline Absent & 26 & $10(38.5)$ & $16(61.5)$ \\
\hline Present & 82 & $52(63.4)$ & $30(36.6)$ \\
\hline \multicolumn{4}{|l|}{ Venous invasion } \\
\hline Absent & 58 & $36(62.1)$ & $22(37.9)$ \\
\hline Present & 50 & $26(52.0)$ & $24(48.0)$ \\
\hline \multicolumn{4}{|l|}{ Dukes' classification $^{\mathrm{c}}$} \\
\hline A & 34 & $10(29.4)$ & $24(70.6)$ \\
\hline $\mathrm{B}$ & 32 & $28(87.5)$ & $4(12.5)$ \\
\hline $\mathrm{C}$ & 32 & $22(68.8)$ & $10(31.2)$ \\
\hline $\mathrm{D}$ & 8 & $2(25.0)$ & $6(75.0)$ \\
\hline \multicolumn{4}{|l|}{ Stage $^{\mathrm{d}}$} \\
\hline I & 30 & $6(20.0)$ & $24(80.0)$ \\
\hline II & 40 & $38(95.0)$ & $2(5.0)$ \\
\hline III & 32 & $16(50.0)$ & $16(50.0)$ \\
\hline IV & 6 & $2(33.3)$ & $4(66.7)$ \\
\hline \multicolumn{4}{|l|}{ Prognosis after surgerye } \\
\hline Disease-free & 66 & $28(42.4)$ & $38(57.6)$ \\
\hline Recurrence and/or metastasis & 42 & $34(81.0)$ & $8(2.0)$ \\
\hline
\end{tabular}

${ }^{a}$ Significant difference $(\mathrm{p}<0.001)$, Mann-Whitney's U test. ${ }^{b}$ Significant difference $(\mathrm{p}<0.05)$, Chi-square for independence test. ${ }^{\mathrm{c}}$ Significant difference $(\mathrm{p}<0.05)$, Mann-Whitney's U test. ${ }^{\mathrm{d}}$ Significant difference between Stage I vs II-IV( $\left.<0.001\right)$, Chi-square for independence test. eSignificant difference $(\mathrm{p}<0.001)$, Chi-square for independence test. 


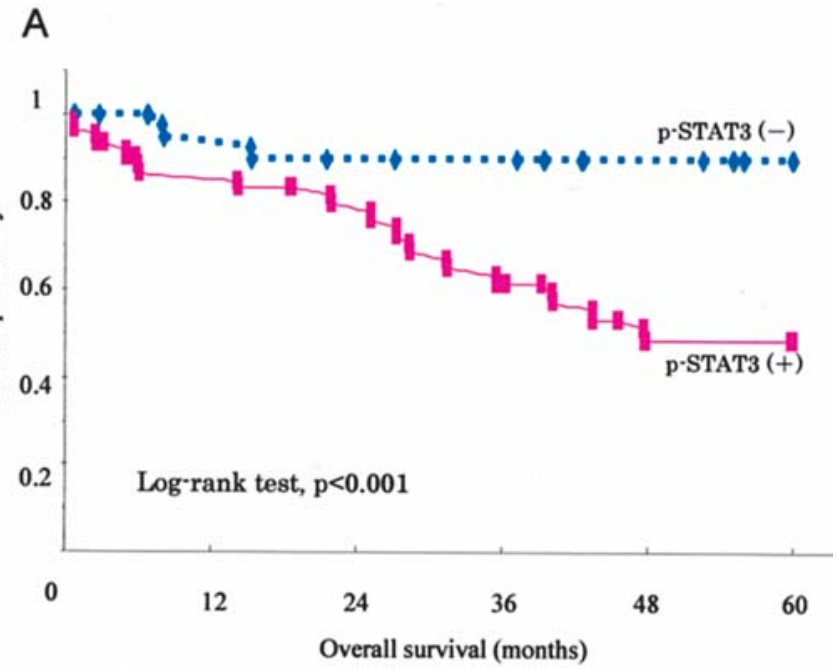

B

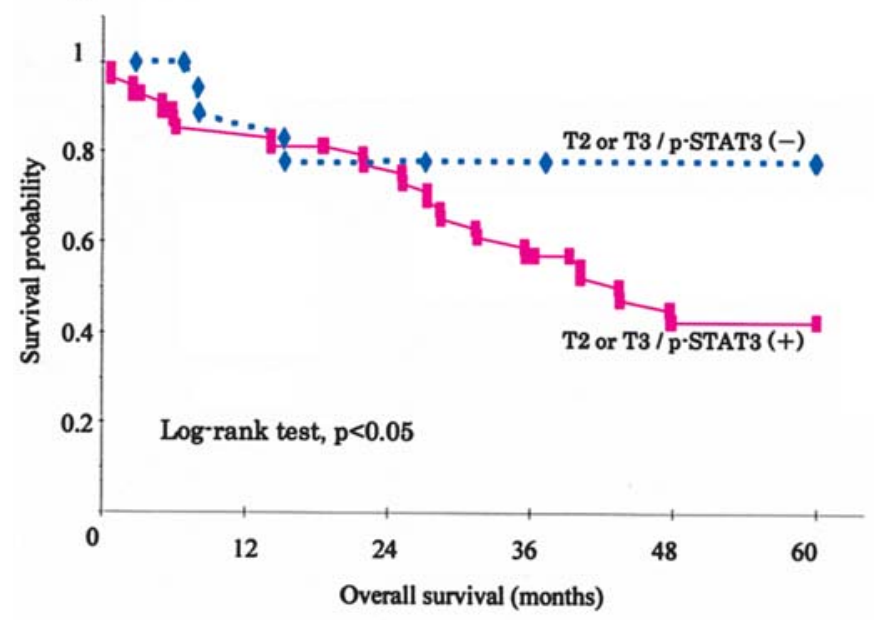

Figure 3. p-STAT3 Kaplan-Meier survival curves in colorectal cancer: (A) overall survival as a function of results of p-STAT3 staining, (B) overall survival as a function of results of both p-STAT3 staining and depth grading of T2 or T3 stage tumor invasion, (C) overall survival as a function of results of both p-STAT3 staining and Dukes' classification, (D) overall survival as a function of results of both p-STAT3 staining and stage, (E) overall survival as a function of results of both p-STAT3 staining and lymphatic invasion.

with depth grading of tumour invasion (T stage), Dukes' classification, stage, and the presence of lymphatic invasion. However, there were no differences in disease-free survival (data not shown).

\section{Discussion}

Recently, many reports have suggested an important role for constitutively activated STAT3 in malignant transformation and tumour progression (25). In our previous study, we reported on the correlation between the expression of p-STAT3 and the depth grading of tumour invasion in human colorectal adenocarcinomas (16). In the present study, the expression of p-STAT3 was found to be more intense in the deeper invasive areas, as shown in Table I. However, there was no correlation between p-STAT3 immunoreactivity and the presence of lymph node metastasis and venous invasion. The main purpose of this study was to examine p-STAT3
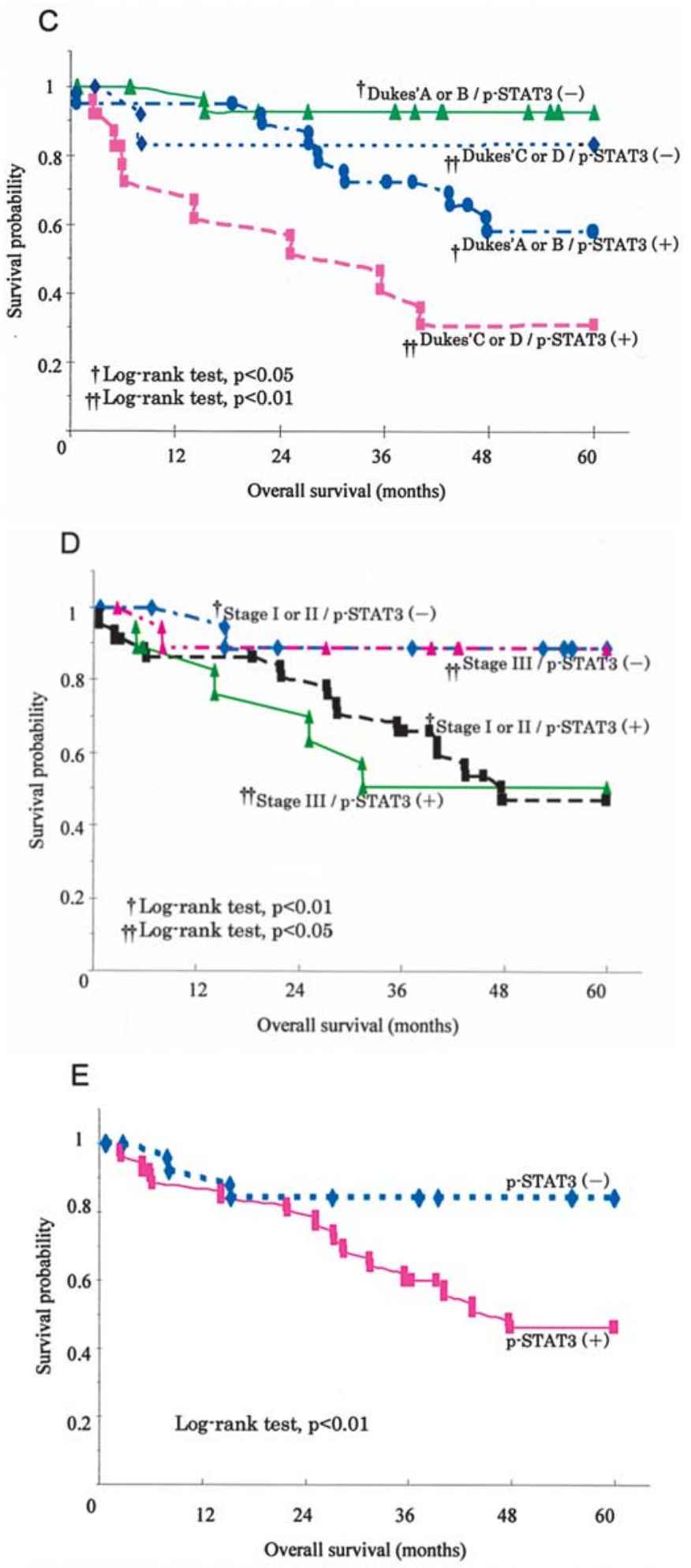

expression and its potential role in the prognosis for human colorectal cancer.

We found a correlation between the expression of p-STAT3 and a poor prognosis in human colorectal cancer. In previous studies, the expression of p-STAT3 was found to be more intense in the deeper invasive areas $(16,26,27)$ and so was thought that there might be a correlation between expression of p-STAT3 and prognosis in human malignancies. However, only a few studies have reported such a correlation (26-29). 
Dolled-Filhart et al and Hsiao et al found that good prognoses were related to p-STAT3 expression in node-negative breast cancer and nasopharyngeal cancer, respectively $(28,29)$. In contrast, Horiguchi et al, Masuda et al, and Gong et al found that poor prognoses were related to the expression of p-STAT3 in renal cell cancer, head and neck squamous cell carcinoma, and gastric cancer, respectively $(26,27,30)$. We suggest that these discrepancies in prognosis prediction may have occurred because the examined cancers originated in different organs. Our study on human colorectal cancer is, to our knowledge, the first one to report a significant correlation of p-STAT3 expression with poor prognosis in this type of cancer.

Prognosis has been considered to correlate with tumour invasion and metastasis (16,26-31). Constitutively activated STAT3 regulates tumour growth and invasion by affecting the expression of genes related to tumour invasion and cell survival (32-39). The present study showed a significant correlation between p-STAT3 expression and poor prognosis. Our results may reflect the importance of p-STAT3 in tumour invasion.

Although downstream events from constitutively activated STAT3 are not adequately revealed, many studies have indicated that its expression in human malignancies is responsible for malignant progression because of the upregulation of cell cycle progression and the prevention of apoptosis (36-40).

Overexpression of p-STAT3 was frequently found in human colorectal carcinoma and its expression was associated with depth grading of tumour invasion and poor prognosis. We considered a potential correlation between the expression of p-STAT3 and prognosis for each $\mathrm{T}$ grade but found no correlation. The expression of p-STAT3 may have an important function in invasion rather than tumour formation. Although the expression of p-STAT3 correlated with a poor prognosis in this study, the prognostic significance of p-STAT3 must be confirmed in additional studies.

\section{References}

1. Parkin DM, Pisani P and Ferlay J: Estimates of the worldwide incidence of eighteen major cancers in 1985. Int J Cancer 54: 594-606, 1993.

2. Finlay IG and Pickford IR: Colorectal carcinoma. In: Current Medicine. Lawson DH, (ed). 4th edition. Churchill Livingstone, Edinburgh, pp51-64, 1994.

3. Yiu HY, Whittemore AS and Shibata A: Increasing colorectal cancer incidence rates in Japan. Int J Cancer 109: 777-781, 2004.

4. Newland RC, Dent OF, Lyttle MN, Chapuis PH and Bokey EL: Pathologic determinants of survival associated with colon or rectal cancer with lymph node metastases: a multivariate analysis of 579 patients. Cancer 73: 2076-2082, 1994.

5. Steinberg SM, Barwick KW and Stablein DM: Importance of tumor pathology and morphology in patients with surgically resected colon cancer. Findings from the Gastrointestinal Tumor Study Group. Cancer 58: 1340-1345, 1986.

6. Takeda K, Noguchi K, Shi W, Tanaka T, Matsumoto M, Yoshida N, Kishimoto T and Akira S: Targeted disruption of the mouse Stat3 gene leads to early embryonic lethality. Proc Natl Acad Sci USA 94: 3801-3804, 1997.

7. Darnell JE Jr: STATs and gene regulation. Science 277: 1630-1635, 1997.

8. Zhong Z, Wen Z and Darnell JE Jr: Stat3 and Stat4: members of the family of signal transducers and activators of transcription. Proc Natl Acad Sci USA 91: 4806-4810, 1994.

9. Chakraborty A and Tweardy DJ: Stat3 and G-CSF-induced myeloid differentiation. Leuk Lymphoma 30: 433-442, 1998.

10. Chakraborty A and Tweardy DJ: Granulocyte colony-stimulating factor activates a $72 \mathrm{kDa}$ isoform of Stat 3 in human neutrophils. J Leukoc Biol 64: 675-680, 1998.
11. Zhong Z, Wen Z and Darnell JE Jr: Stat3: a STAT family member activated by tyrosine phosphorylation in response to epidermal growth factor and interleukin-6. Science 264: 95-98, 1994.

12. Scholz A, Heinze S, Detjen KM, Peters M, Welzel M, Hauff P, Schirner M, Wiedenmann B and Rosewicz S: Activated signal transducer and activator of transcription 3 (STAT3) supports the malignant phenotype of human pancreatic cancer. Gastroenterology 125: 891-905, 2003.

13. Bowman T, Garcia R, Turkson J and Jove R: STATs in oncogenesis. Oncogene 19: 2474-2488, 2000.

14. Huang M, Page C, Reynolds RK and Lin J: Constitutive activation of stat 3 oncogene product in human ovarian carcinoma cells. Gynecol Oncol 79: 67-73, 2000.

15. Song JI and Grandis JR: STAT signaling in head and neck cancer. Oncogene 19: 2489-2495, 2000.

16. Kusaba T, Nakayama T, Yamazumi K, Yakata Y, Yoshizaki A, Nagayasu T and Sekine I: Expression of p-STAT3 in human colorectal adenocarcinoma and adenoma; correlation with clinicopathological factors. J Clin Pathol 58: 833-838, 2005.

17. Jass JR and Sobin LH: Histological Typing of Intestinal Tumors. 2nd edition. Springer-Verlag, Berlin, 1989.

18. AJCC cancer staging manual. Greene FL, Page DL, Fleming ID, Fritz AG, Balch CM and Haller DG, (eds). 6th edition. Springer, New York, pp127-129, 2002.

19. Dukes CE: The classification of cancer of the rectum. J Pathol Bacteriol 35: 323-332, 1932.

20. Dukes CE: The surgical pathology of rectal cancer. J Clin Pathol 2: 95-98, 1949.

21. Whittaker $\mathbf{M}$ and Goligher JC: The prognosis after surgical treatment for carcinoma of the rectum. Br J Surg 63: 384-388, 1976.

22. Seefeld PH and Bargen JA: The spread of cancer of the rectum: invasion of the lymphatics, veins and nerves. Ann Surg 118: 76-89, 1943.

23. Talbot IC, Ritchie S, Leighton M, Hughes AO, Bussey HJ and Morson BC: Invasion of veins by carcinoma of rectum: method of detection, histological features and significance. Histopathology 5: 141-163, 1981 .

24. Campbell CL, Jiang Z, Savarese DM and Savarese TM: Increased expression of the interleukin-11 receptor and evidence of STAT3 activation in prostate carcinoma. Am J Pathol 158: 25-32, 2001.

25. Bromberg J: Stat proteins and oncogenesis. J Clin Invest 109: 1139-1142, 2002.

26. Horiguchi A, Oya M, Shimada T, Uchida A, Marumo K and Murai M: Activation of signal transducer and activator of transcription 3 in renal cell carcinoma: a study of incidence and its association with pathological features and clinical outcome. J Urology 168: 762-765, 2002.

27. Masuda M, Suzui M, Yasumatu R, Nakashima T, Kuratomi Y, Azuma K, Tomita K, Komiyama S and Bernard Weinstein I: Constitutive activation of signal transducers and activators of transcription 3 correlates with cyclin D1 overexpression and may provide a novel prognostic marker in head and neck squamous cell carcinoma. Cancer Research 62: 3351-3355, 2002.

28. Dolled-Filhart M, Camp RL, Kowalski DP, Smith BL and Rimm DL: Tissue microarray analysis of signal transducers and activators of transcription 3 (Stat3) and phospho-Stat3 (Tyr705) in node-negative breast cancer shows nuclear localization is associated with a better prognosis. Clin Cancer Res 9: 594-600, 2003.

29. Hsiao JR, Jin YT, Tsai ST, Shiau AL, Wu CL and Su WC: Constitutive activation of STAT3 and STAT5 is present in the majority of nasopharyngeal carcinoma and correlates with better prognosis. Br J Cancer 89: 344-349, 2003.

30. Gong W, Wang L, Yao JC, Ajani JA, Wei D, Aldape KD, Xie K, Sawaya R and Huang S: Expression of activated signal transducer and activator of transcription 3 predicts expression of vascular endothelial growth factor in and angiogenic phenotype of human gastric cancer. Clin Cancer Res 11: 1386-1393, 2005.

31. Ma XT, Wang S, Ye YJ, Du RY, Cui ZR and Somsouk M: Constitutive activation of Stat 3 signaling pathway in human colorectal carcinoma. World J Gastroenterol 10: 1569-1573, 2004.

32. Xie TX, Wei D, Liu M, Gao AC, Ali-Osman F, Sawaya R and Huang S: Stat3 activation regulates the expression of matrix metalloproteinase- 2 and tumor invasion and metastasis. Oncogene 23: 3550-3560, 2004. 
33. Emmert-Buck MR, Roth MJ, Zhuang Z, Campo E, Rozhin J, Sloane BF, Liotta LA and Stetler-Stevenson WG: Increased gelatinase A (MMP-2) and cathepsin B activity in invasive tumor regions of human colon cancer samples. Am J Pathol 145: 1285-1290, 1994

34. Niu G, Wright KL, Huang M, Song L, Haura E, Turkson J, Zhang S, Wang T, Sinibaldi D, Coppola D, Heller R, Ellis LM, Karras J, Bromberg J, Pardoll D, Jove R and Yu H: Constitutive Stat3 activity up-regulates VEGF expression and tumor angiogenesis. Oncogene 21: 2000-2008, 2002.

35. Wei LH, Kuo ML, Chen CA, Chou CH, Lai KB, Lee CN and Hsieh CY: Interleukin-6 promotes cervical tumor growth by VEGF-dependent angiogenesis via a STAT3 pathway. Oncogene 22: $1517-1527,2003$

36. Bromberg JF, Wrzeszczynska MH, Devgan G, Zhao Y, Pestell RG, Albanese C and Darnell JE Jr: Stat3 as an oncogene. Cell 98: 295-303, 1999.
37. Nakajima K, Yamanaka Y, Nakae K, Kojima H, Ichiba M, Kiuchi N, Kitaoka T, Fukada T, Hibi M and Hirano T: A central role for Stat3 in IL-6-induced regulation of growth and differentiation in M1 leukemia cells. EMBO J 15: 3651-3658, 1996.

38. Catlett-Falcone R, Landowski TH, Oshiro MM, Turkson J, Levitzki A, Savino R, Ciliberto G, Moscinski L, FernandezLuna JL, Nunez G, Dalton WS and Jove R: Constitutive activation of Stat 3 signaling confers resistance to apoptosis in human U266 myeloma cells. Immunity 10: 105-115, 1999.

39. Niu G, Bowman T, Huang M, Shivers S, Reintgen D, Daud A, Chang A, Kraker A, Jove R and Yu H: Roles of activated Src and Stat3 signaling in melanoma tumor cell growth. Oncogene 21: 7001-7010, 2002

40. Kanda N, Seno H, Konda Y, Marusawa H, Kanai M, Nakajima T, Kawashima T, Nanakin A, Sawabu T, Uenoyama Y, Sekikawa A, Kawada M, Suzuki K, Kayahara T, Fukui H, Sawada M and Chiba T: STAT3 is constitutively activated and supports cell survival in association with survivin expression in gastric cancer cells. Oncogene 23: 4921-4929, 2004. 